\title{
The relationship of personality determinants of children with coping strategies in difficult situations
}

\author{
Tatyana Aparchina*, Tatyana Kiseleva, Sergey Talanov, and Dmitry Berezin \\ Yaroslavl State Pedagogical University named after K.D. Ushinsky, Russia
}

\begin{abstract}
The article presents the results of a comparative analysis of the personal characteristics of children who find themselves in a difficult life situation. The subject of the study was the coping strategies for behavior in stressful situations. The authors used the method of diagnosis of coping mechanisms of E. Heim and Lazarus coping test. The testee's dominant strategy was confrontation, which exacerbates social deviations and affects the formation of the personality of a child. Features of the formation of the personality of such children is an increased level of psychoticism and neuroticism. Emotional instability and imbalance of children makes it complicated to form constructive communication skills, and leads to social isolation. The latter, in turn, becomes the trigger for the formation of secondary social disorders. Dominant selfish and egocentric manifestations strengthen the increased level of conflict, not contributing to the formation of skills for constructive solutions to difficulties. Material support from the state do not solve, but exacerbate the situation, provoking the formation of a consumer position. The authors of the article believe that changing the situation requires comprehensive psychological and pedagogical support and follow up throughout childhood, not only for the child, but also his family.
\end{abstract}

\section{Introduction}

Modern Russia is constantly experiencing various shocks and crises: economic, political, environmental, social, etc. As a result of instability and uncertainty, some families, and, consequently, children, find themselves in difficult life situations (hereinafter - DLS). Unfortunately, the number of such children is not reducing. The "State report on the situation of children and families with children in the Russian Federation" noted that in 2017 the population with cash incomes below the subsistence level was 19.3 million people or $13.2 \%$ of the total population [1] Therefore, increased attention is paid to children in DLS [2]. The category of children in difficult situations is defined by the Federal Law of July 24, 1998 No. 124-FZ "About Basic Guarantees of the Rights of the Child in the Russian Federation" [3]. For teachers and psychologists (L.A. Sitak, E.G. Larionova, T.I. Lavryonova, M.A. Lygina), the issue of socio-pedagogical and socio-psychological support

\footnotetext{
* Corresponding author: aparchina@mail.ru
} 
for children in DLS is becoming extremely important, as well as assistance, provision, accompaniment in the process of socialization of such a child, prevention of secondary deviations and other social problems (alcohol and drug addiction, vagrancy, theft, etc.) $[4,5]$. To solve this problem, it is necessary to clearly understand the mechanisms of socialization and especially the formation of the personality of such a child. For all the variety of conditions and factors affecting personality formation, the fact that there is a difficult life situation remains common for the analyzed category, which is crucial for the socialization of the child, determining the social situation of his development, especially in a transitive society.

\section{Purpose of research}

The aim of our study was to highlight individual typological features that determine the specifics of the formation of a child's personality in DLS, and the relationship of these characteristics with coping strategies of behavior. L. Murphy and R. Lazarus introduced the term "coping strategies" to describe ways to overcome the crisis, later they began to use it more often to describe ways to overcome stress [6]. For the purposes of our study, both understandings are valid because DLS can be considered as a temporary phenomenon, then it acquires the attributes of a stressful situation, or as a certain period of life, longer in time, then this situation falls under the classification of life crises.

\section{Methodical apparatus of research}

For the study, two complementary methods were used: the method of diagnosing the coping mechanisms of E. Heim (adapted in the laboratory of clinical psychology of the Psychological and Neurological Institute named after V.M. Bekhterev, under the direction of L.I. Wasserman) [7] and the Lazarus coping test (adapted by T. L. Kryukova, E. V. Kuftyak, M. S. Zamyshlyaeva) [8]. The sample of subjects was presented in two groups: the experimental group consisted of adolescents from 11 to 15 years old, belonging to the category of children in DLS. The total number of this group was 68 people, of which 41 were boys, 27 girls; while children without parental care amounted to $31 \%$; children with disabilities - $15 \%$, children of victims of domestic violence - $10 \%$; children in educational institutions for students with deviant (socially dangerous) behavior, 29\%; children living in poor families - $15 \%$. The control group consisted of their peers living and raising in full families. Groups were equalized by gender and age.

Based on the analysis of psychological and pedagogical literature, a number of factors were identified that have a dominant role in the formation of the personality of a child who finds himself in DLS. Next, a comparison was made of the selected groups using a row of psychological tests. The results obtained were subjected to statistical verification of the significance of differences using t-criteria by Student [9]. This part of the study allowed us to single out the following personality determinants, which we analyzed in relation to the coping strategies used: extraversion / introversion, self-control, aggressiveness, subjective feeling of loneliness, internality / externality. To process the obtained results, a correlation analysis was used, the results of which are summarized in table 1.

\section{Results and its discussion}

Note that several strategies are not presented in the behavioral repertoire of children caught up in DLS. So, they do not seek social support in a constructive context, on the contrary, such children take a dependent-consumer position, trying to get everything ready-made, 
without putting their own efforts. If they are faced with a situation in which they require their own activity or initiative, then this causes bursts of aggression and irritability. Unfortunately, these children do not have long-term planning skills, so they cannot transfer these skills to planning problems and finding ways to prevent problems in the future. The analyzed category of children is distinguished by a very short time perspective, since it does not exceed six months in adolescents, beyond this period it is difficult for them to describe the events that they are waiting and planning. Many of them are characterized by a pessimistic-negative assessment of any occurring event, it is extremely difficult for them to find pluses by positively overestimating themselves, their relationships, their relatives and friends, as a result of which these children are constantly waiting for themselves some troubles, surprises and problems; it is difficult for them to accept selfless help; the formation of an epileptoid type of personality accentuation is possible. For ease of perception, only those factors are listed in Table 1 for which correlation relationships take place.

Table 1. Intercorrelation matrix

\begin{tabular}{|c|c|c|c|c|c|c|c|}
\hline Factors & 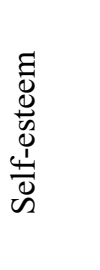 & 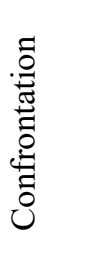 & 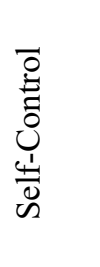 & 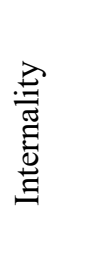 & 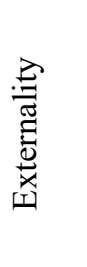 & 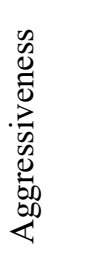 & 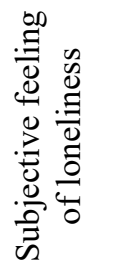 \\
\hline Neuroticism & $-0,44$ & $\mathbf{0 , 5 8}$ & $-0,27$ & $-0,12$ & 0,2 & 0,4 & 0,22 \\
\hline Psychoticism & 0,06 & 0,29 & $-0,35$ & $-0,03$ & 0,12 & 0,59 & 0,4 \\
\hline Confrontation & & & $-0,45$ & $-0,2$ & 0,26 & 0,44 & 0,2 \\
\hline $\begin{array}{l}\text { Acceptance of } \\
\text { responsibility }\end{array}$ & & & & 0,64 & $-0,6$ & $-0,17$ & $-0,02$ \\
\hline
\end{tabular}

Note. Significant correlations are highlighted in bold in the table, $\mathrm{p}=0.05$

A negative correlation of neuroticism and self-esteem leads to a high level of anxiety, in which the child in DLS is not sure of the success of his activity, has a loser attitude, which is reinforced by problems in the family in reality, the lack of psychological support, as a result, leads to a decrease in self-esteem, passivity, unwillingness and inability to solve their problems, shifting solutions to other people. On the other hand, neuroticism is characterized by high emotional instability, impulsive behavior, outbreaks of aggression, which together leads to the formation of confrontational coping as a means of solving problems. The higher the tendency to neuroticism, the greater the likelihood that in a stressful situation a child with issues will choose confrontational coping, which will aggravate relations with parents, teachers, and peers. Neuroticism is characterized by high emotional instability, aggressiveness in the children we study is often manifested in the form of bright "outbreaks". The higher the level of neuroticism, the higher the likelihood of outbreaks of aggression.

The uncertainty and instability associated with the difficulties of a life situation provoke an increase in psychoticism of children in DLS, which is characterized by inadequate emotional responses even to an externally neutral stimulus. Parents, acting as role models, 
reference persons for their child, set inappropriate behavioral patterns, since they themselves are not able to cope with difficulties, are not capable of long-term planning and predicting situations, which further aggravate the severity and difficulty of the life situation. It is the parents who can break down, throw out their internal discontent and dissatisfaction with the child, show aggression, demonstrate family violence and suppress the personality of the child. We believe that in families in DLS there is a direct relationship between the level of psychoticism of parents and children, as a result, the higher the level of psychoticism, the greater the tendency to aggressiveness in both parents and children. Uncontrolled behavior of the child in DLS, poorly predicted for those around him, leads to an increase in communicative difficulties, which negatively affects relations with peers in the children's team. Explosive behavior, external signs of ill-being, low financial situation in the aggregate of these and other factors make the child in DLS unpopular among peers, and in some cases even openly rejected or ignored. With this circumstance, we explain the positive correlation between psychoticism and the subjective feeling of loneliness. Psychoticism causes a tendency to seclusion, as a result of which the circle of social contacts, close friends may be insignificant or even absent, resulting in a subjective feeling of loneliness, or withdrawal into a virtual space where you can hide your social status. The latter circumstance allows us to predict the formation of a child in DLS predisposition to Internet addiction.

Out of all the variety of coping strategies, children who find themselves in DLS are significantly more likely than others to choose confrontation. The internal rejection of themselves, their characteristics in these children translates into confrontation with their peers, and in their reports, respondents in most cases took an accusatory position with respect to their peers, transferring responsibility for conflict relations to them. Such a behavior model does not contribute to solving life problems; moreover, it deprives children who are in DLS of the opportunity to use external resources, support their social environment, and support their peers. When confrontational coping is realized in the studied category of children, impulsive behavior is observed, and an extremely low level of self-control. With unformed communication skills, the pattern described above leads to rejection of such a child by society, forms a marginal type of personality. The situation is aggravated by the fact that, when a confrontational model of behavior is implemented, coping actions lose their focus and become mainly the result of the release of emotional tension, one of which becomes aggression (verbal, non-verbal, direct or indirect).

Unfortunately, the results of the study show a clear predominance of confrontation among the dominant coping strategies that are used in everyday communication by children who find themselves in DLS. But, if the child managed to formulate a strategy of acceptance of responsibility, then the level of socialization of such children is much higher than that of other peers, which confirms the positive correlation between the strategy of acceptance of responsibility and the internal locus of control. Such a coping strategy involves the recognition by the subject of his role in the occurrence of the problem and taking responsibility for its solution. Children with an internal locus of control explain what is happening to them and their family as a result of their own actions. The higher the level of subjective control, the more likely it is to use a strategy for taking responsibility.

Conclusion. Summing up the results of the study, we would like to highlight the priority areas of socio-psychological support and support for a child who is in DLS, which would form a wider range of coping strategies that would contribute to the socialization and social adaptation of such a child. First of all, such a child needs sport, and the particular sport does not matter and depends on the individual capabilities of the person, the main thing that sports people give is the ability to set a certain level of achievements, a certain height and purposefully move towards its conquest. Victories in sports will help increase self-esteem, self-confidence and one's capabilities. The choice of team sports is preferable, 
because in addition to the above effects, favorable conditions will be created for the formation of communication skills, the ability to ask for help yourself and provide it to other people. Thanks to the mechanisms of sublimation, unconstructive aggression can be relatively easily transformed into sporting achievement. In second place in the system of psychological support and accompaniment of a child in DLS can be hiking, camps, traveling (preferably walking), climbing mountains, river rafting, suggesting the formation of survival skills in physically difficult conditions. To the positive results of socialization and the formation of constructive coping strategies, which were mentioned above when assessing the role of sport, we can add the effect of imitation of the reference person, since in such conditions there must necessarily be a leader, guide, mentor who himself has the maximum degree to overcome various difficulties. And finally, we believe that the for children in DLS participation in volunteer activities will create conditions for the analysis and reflection of their own situation, the ability to compare their own situation and the situation in which people who are disinterested help are. The very fact that from the petitioner and consumer the considered category of children becomes a subject that itself supports, provides real help to those in need, can become a trigger for reassessing their life situation and choosing a different behavior strategy. The above-noted areas of psychological and pedagogical works in combination with traditional trainings of personal growth and behavioral trainings formed the basis of the correctional-developmental program for children and adolescents who find themselves in DLS. This program is implemented at an interdepartmental level by the forces of educational organizations, social protection and support organizations, health care organizations, as well as youth work organizations. Currently, this program is being tested in the Yaroslavl region.

\section{References}

1. State report About the situation of children and families with children in the Russian Federation for 2017 (2018)

2. Children in difficult situations: New approaches to solving problems /Support Fund for children in difficult situations. 26 (2010)

3. Federal Law of July 24, 1998 No. 124-FZ "On Basic Guarantees of the Rights of the Child in the Russian Federation" (1998)

4. L.A. Sitak, E.G. Larionova. Children in difficult life situations and their sociopedagogical characteristics. 71-75 (2017)

5. T.I. Lavrenova, M.A. Lygina. Social support and support for children in difficult life situations. Sociosphere. 3, 55-60 (2011).

6. R. Lazarus Emotion and Adaptation. NY 557 (1991)

7. E. Heim. Coping und Adaptivitat: Gibt es geeignetes oder ungeeignetes Coping Psychot, Psychosom., Med. Psychologie. 1, 8-17 (1988).

8. R. Lazarus, S. Folkman Stress, Appraisal and Coping. NY, 218 (1984)

9. T.G. Kiseleva. Development of personal effectiveness skills as a means of socializing high school students. Yaroslavl: RIO YSPU, 32-37 (2017) 